\title{
Contribution of acetate to butyrate formation by human faecal bacteria
}

\author{
Sylvia H. Duncan ${ }^{1}$, Grietje Holtrop ${ }^{2}$, Gerald E. Lobley ${ }^{1}$, A. Graham Calder ${ }^{1}$, Colin S. Stewart ${ }^{1}$ \\ and Harry J. Flint ${ }^{1 *}$ \\ ${ }^{1}$ Gut Microbiology and Immunology Division, and \\ ${ }^{2}$ Biomathematics and Statistics Scotland, Rowett Research Institute, Greenburn Road, Bucksburn, \\ Aberdeen AB21 9SB, UK
}

(Received 29 October 2003 - Revised 10 February 2004 - Accepted 17 February 2004)

\begin{abstract}
Acetate is normally regarded as an endproduct of anaerobic fermentation, but butyrate-producing bacteria found in the human colon can be net utilisers of acetate. The butyrate formed provides a fuel for epithelial cells of the large intestine and influences colonic health. $\left[1-{ }^{13} \mathrm{C}\right]$ Acetate was used to investigate the contribution of exogenous acetate to butyrate formation. Faecalibacterium prausnitzii and Roseburia spp. grown in the presence of $60 \mathrm{~mm}$-acetate and $10 \mathrm{~mm}$-glucose derived $85-90 \%$ butyrate-C from external acetate. This was due to rapid interchange between extracellular acetate and intracellular acetyl-CoA, plus net acetate uptake. In contrast, a Coprococcus-related strain that is a net acetate producer derived only $28 \%$ butyrate-C from external acetate. Different carbohydrate-derived energy sources affected butyrate formation by mixed human faecal bacteria growing in continuous or batch cultures. The ranking order of butyrate production rates was amylopectin $>$ oat xylan $>$ shredded wheat $>$ inulin $>$ pectin (continuous cultures), and inulin $>$ amylopectin $>$ oat xylan $>$ shredded wheat $>$ pectin (batch cultures). The contribution of external acetate to butyrate formation in these experiments ranged from 56 (pectin) to $90 \%$ (xylan) in continuous cultures, and from 72 to $91 \%$ in the batch cultures. This is consistent with a major role for bacteria related to $F$. prausnitzii and Roseburia spp. in butyrate formation from a range of substrates that are fermented in the large intestine. Variations in the dominant metabolic type of butyrate producer between individuals or with variations in diet are not ruled out, however, and could influence butyrate supply in the large intestine.
\end{abstract}

Roseburia intestinalis: Faecalibacterium prausnitzii: Butyrate synthesis: Acetate: Stable isotope: Colon

SCFA are the main products of anaerobic microbial fermentation in the large intestine and affect colonic health by providing energy to the epithelial cells (Csordas, 1996). Butyrate, in particular, has important effects on development and gene expression in intestinal cells (Csordas, 1996; Avivi-Green et al. 2000; Mariadason et al. 2000; Cavaglieri et al. 2003) and is generally thought to play a protective role against colorectal cancer and colitis (McIntyre et al. 1993; Hague et al. 1995; Wachterhauser \& Stein, 2000; Scheppach et al. 2001). The concentrations and, thus, relative proportions of different SCFA in the colon are affected by the composition of the diet, in particular the type and quantity of substrates that survive to the large intestine (Cummings, 1995; Macfarlane \& Gibson, 1997; Wolin et al. 1999). The relationship between fermentable carbohydrates and metabolic output, however, depends critically on the composition of the microbial community and the metabolic characteristics of individual anaerobic bacteria. Understanding the interactions within the gut microbial community, therefore, is essential in devising strategies to enhance gut health by nutritional means (Pryde et al. 2002).

In pure culture, different anaerobic gut bacteria can produce a wide variety of products, including acetate, propionate, butyrate, succinate, lactate and ethanol, but only the first three are normally found as major products in the mixed gut ecosystem (Macfarlane \& Gibson, 1997). This is largely explained by the fact that products such as lactate and succinate are efficiently utilised by certain groups of anaerobic bacteria. Although acetate reaches the highest concentration of any of the SCFA in faeces, it is known that many human faecal bacteria are net consumers of acetate in pure culture (Barcenilla et al. 2000). Acetate-consumers include two important groups of butyrate producers, Faecalibacterium prausnitzii and the Roseburia intestinalis/Eubacterium rectale, and many strains require acetate for optimal growth (Duncan et al. 2002a,c; Hold et al. 2003). Rather than just representing a stable endproduct, turnover of acetate in the colonic lumen would be expected, with a significant contribution by acetate to

\footnotetext{
Abbreviation: MPE, molar \% excess.

* Corresponding author: Professor Harry J. Flint, fax + 441224 716687, email hjf@rri.sari.ac.uk
} 
butyrate synthesis. Interestingly, there are already indications from earlier work that labelled $\mathrm{CO}_{2}$ can be incorporated first into acetate by reductive acetogenesis, and then into butyrate, when faecal material is incubated in the presence of glucose and endogenous substrates (Miller \& Wolin, 1996; Wolin et al. 1999).

In the present study, the contribution of acetate to butyrate formation was investigated directly using $\left[{ }^{13} \mathrm{C}\right]$ acetate. The present results show very substantial incorporation of acetate-C into butyrate, both in pure cultures of major butyrate-producing bacteria from the human gut (Barcenilla et al. 2000; Duncan et al. 2002a,c; Hold et al. 2003) and in batch and continuous-flow fermentor incubations of mixed bacterial populations from human faeces. We also demonstrated that the rate of butyrate formation and the contribution of acetate to butyrate formation can vary with the species of butyrate-producing bacterium and with the type of fermentable carbohydrate.

\section{Materials and methods}

\section{Bacterial strains and maintenance}

Bacterial strains were from the Rowett Research Institute culture collection; certain strains are also available from the DSM (Deutsche Sammlung von Mikroorganismeu und Zollkultureu $\mathrm{GMbH}$ ), as indicated later. Isolation of the butyrate-producing isolates Roseburia sp. (A2-181 and A2183), Roseburia intestinalis (L1-82 (DSM14610 ${ }^{\mathrm{T}}$ ) and L18151), F. prausnitzii (A2-165) and Coprococcus-related sp. (L2-50) from human faeces was reported previously (Barcenilla et al. 2000). R. intestinalis strains L1-82 and L1-8151 were isolated from a healthy male infant (11 months old) and the Coprococcus related strain (L2-50) was isolated from a faecal sample from the same infant $(2$ years old); the two Roseburia sp. strains (A2-181 and A2183 ) and the $F$. prausnitzii strain (A2-165) were all isolated from a female adult on a normal diet. The anaerobic medium M2 incorporating $2 \mathrm{~g}$ of the three $\mathrm{C}$ sources (glucose, soluble starch and cellobiose/l M2GSC medium) (Miyazaki et al. 1997) was used for the routine maintenance of the bacterial isolates. The medium was dispensed into Hungate tubes sealed with butyl septum stoppers (Bellco Glass Inc., Vineland, NJ, USA) following the anaerobic method, in which the medium is prepared and maintained under $\mathrm{O}_{2}$-free $\mathrm{CO}_{2}$ (Bryant, 1972).

For kinetic studies, the isolates (approximately $1 \times 10^{7}$ cells per ml medium) were incubated at $37^{\circ} \mathrm{C}$ in the presence of $10 \mathrm{~mm}$-glucose and $3 \mathrm{~mm}$-acetate containing $\left[1-{ }^{13} \mathrm{C}\right]$ acetate to give 6 molar $\%$ excess (MPE), similar to the conditions described by Duncan et al. (2002b). Tubes were prepared in triplicate and analysed after incubation for $1 \cdot 0,2 \cdot 0,3 \cdot 0,4 \cdot 0,5 \cdot 0,6 \cdot 0,7 \cdot 0,8 \cdot 0,9 \cdot 0,10 \cdot 0$, $11 \cdot 0,12 \cdot 0,13 \cdot 0,14 \cdot 5,24 \cdot 0$ and $32 \cdot 0 \mathrm{~h}$.

\section{Collection and preparation of faecal samples}

Fresh faecal samples were provided by a healthy male volunteer (50 years old). The volunteer did not take any antibiotics or drugs known to influence faecal microbiota during the 6 months before the start of the studies. Each fermentor vessel was inoculated with $5 \mathrm{~g}$ wet weight of faeces. For the batch culture incubations, a faecal slurry $(200 \mathrm{~g} / \mathrm{l})$ was prepared in anaerobic PBS and $1 \mathrm{ml}$ slurry was added to $9 \mathrm{ml}$ medium under anaerobic conditions.

\section{Simulated human colonic fermentor studies}

The studies were conducted in duplicate single-stage fermentor systems based on the model described by Macfarlane et al. (1989). The fermentor medium (Hillman et al. 1994) consisted of a mixture of the following $\mathrm{C}$ sources: potato starch $(5.0 \mathrm{~g} / \mathrm{l})$ and xylan, pectin, amylopectin and arabinogalactan $(0.6 \mathrm{~g} / \mathrm{l}$ each). The initial mixture of carbohydrates in the feed flasks (decribed earlier) was subsequently replaced on a $7 \mathrm{~d}$ cycle with each of the specific compounds: amylopectin, pectin, inulin (dahlia; Dahlia, sp.), xylan, inulin (chicory; Cichorium iutybus) and pancreatin-treated shredded wheat, in that order, to give a final concentration of $5 \cdot 0 \mathrm{~g} / \mathrm{l}$, as described by Duncan et al. (2003). The shredded wheat was prepared by incubation with $10 \mathrm{mg}$ pepsin/g at $\mathrm{pH} 2.3$ for $30 \mathrm{~min}$ at $37^{\circ} \mathrm{C}$. The $\mathrm{pH}$ was adjusted to 7.5 and material incubated with $40 \mathrm{mg}$ pancreatin/g. The solids from the pre-treated material were pelleted by centrifugation at $6000 \mathrm{~g}$ for $15 \mathrm{~min}$ and washed twice in sterile water. The solid material was freeze-dried before use.

The growth medium was maintained under a stream of $\mathrm{CO}_{2}$. The volume of the medium in the fermentor vessel was kept constant at $250 \mathrm{ml}$, with a flow rate of fresh medium (containing $2.5 \mathrm{~mm}$-acetate) equal to one liquid pool turnover per $\mathrm{d}$. Both the sterile medium feed flask and fermentor flasks were mixed by internal stirrer bars powered by external stirring units. A $\mathrm{pH}$ controller delivered sterile solutions of $0.5 \mathrm{M}-\mathrm{HCl}$ or $0.5 \mathrm{M}-\mathrm{NaOH}$ to maintain $\mathrm{pH}$ 6.5-6.8; the temperature was maintained at $37^{\circ} \mathrm{C}$ using a thermal jacket. The fermentor vessel was inoculated through a port in the top with a faecal suspension from the same volunteer. Freshly voided faeces $(5 \mathrm{~g})$, suspended under $\mathrm{O}_{2}$-free $\mathrm{CO}_{2}$ in $20 \mathrm{ml} 50 \mathrm{~mm}$-phosphate buffer ( $\mathrm{pH} \mathrm{6.8)} \mathrm{containing} 0.5 \mathrm{~g}$ cysteine/l, were used as the inoculum (giving a starting concentration of $20 \mathrm{~g}$ faeces/l in the fermentor). The fermentor was sampled regularly by the withdrawal of $5 \mathrm{ml}$ through a sampling device to monitor SCFA concentrations throughout the investigation. On day 7 of each incubation, $2 \mathrm{mmol}\left[1-{ }^{13} \mathrm{C}\right]$ acetate (Isotec Ltd, Miamisburg, OH, USA) was added by injection. Samples $(3 \mathrm{ml})$ were then removed at $0 \cdot 16,2 \cdot 00$, $4.00,6 \cdot 00,9.00,12 \cdot 00,24 \cdot 00,33.00$ and $48.00 \mathrm{~h}$ to determine SCFA concentrations and enrichments.

Amylopectin from potato starch was from Fluka (product no. 10118; Gillingham, Dorset); oat spelt xylan (X0627), citrus pectin (P9135), dahlia inulin (I3754), chicory inulin (I2255) and arabinogalactan (A2839) were from Sigma (Poole, Dorset); shredded wheat was from standard retail outlets. Information on solubility is given by Duncan et al. (2003).

\section{Batch culture incubations}

Anaerobic fermentor medium (described earlier; an SCFA mixture containing acetate $\left(28 \mathrm{~mm}\right.$ plus $2 \mathrm{~mm}-\left[1-{ }^{13} \mathrm{C}\right]$ acetate, i.e. a mixture at $6.7 \mathrm{MPE})$, propionate $(9 \mathrm{mM})$, valerate 
$(1.2 \mathrm{~mm})$, isovalerate $(1.2 \mathrm{~mm})$ and isobutyrate $(1.2 \mathrm{~mm})$ (with the exception of one batch of medium that contained amylopectin $(5 \mathrm{~g} / \mathrm{l})$ plus acetate at a final concentration of $60 \mathrm{~mm}$ and $7 \mathrm{MPE}$ with regard to $\left[1{ }^{13} \mathrm{C}\right]$ acetate) $)$ was dispensed in $9 \mathrm{ml}$ portions into Hungate tubes under a stream of $\mathrm{CO}_{2}$. The model dietary substrates were the same as those used in the fermentor studies, but with chicory inulin excluded and glucose included, and the medium was heat sterilised. After cooling, the medium was inoculated with $1 \mathrm{ml}$ faecal slurry $(200 \mathrm{~g} / \mathrm{l})$ under $\mathrm{CO}_{2}$ and incubated at $37^{\circ} \mathrm{C}$. Sample tubes were processed in triplicate to measure SCFA concentrations and ${ }^{13} \mathrm{C}$ enrichments at 0,2 , $4,6,8,10,12,24,30$ and $48 \mathrm{~h}$.

\section{Analysis of $\left[{ }^{13}\right.$ C]acetate and $\left[{ }^{13} \mathrm{C}\right]$ butyrate enrichments}

Concentrations of SCFA were measured either by the GC method based on conversion to the tert-butyldimethylsilyl derivative as described by Richardson et al. (1989), or by isotope dilution. For the latter technique, to portions of the incubation media removed at each time point were added known quantities of $\left[1-{ }^{13} \mathrm{C}\right]$ acetate and $\left[1-{ }^{13} \mathrm{C}\right]$ butyrate to raise the enrichments to approximately $50 \mathrm{MPE}$ (i.e. by addition of an equal mass). These enrichments were then determined (see later) and the concentrations determined from the isotopic dilution as described in principle previously (Calder et al. 1999).

Other portions $(1 \mathrm{ml})$ of the media were acidified with $0.5 \mathrm{ml}$ concentrated $\mathrm{HCl}$ for measurement of isotopic enrichments. The SCFA in these samples (and those for isotope dilution measurements) were converted to the tert-butyldimethylsilyl derivatives (Richardson et al. 1989) and analysed by GC-MS on a Hewlett Packard 5989A MS coupled to a HP 5980 GC (Hewlett Packard, Stockport, Cheshire). The temperatures of the GC injector and of the interface line were 280 and $250^{\circ} \mathrm{C}$ respectively. The tert-butyldimethylsilyl derivatives were separated on a $30 \mathrm{~m} \times 0.25 \mathrm{~mm} \times 0.25$ $\mu$ SE-30 fused silica capillary column (Alltech, Carnforth, Lancs., UK) under the following conditions: $60^{\circ} \mathrm{C}$ for $3 \mathrm{~min}$ then $10^{\circ} \mathrm{C} / \mathrm{min}$ to $210^{\circ} \mathrm{C}$ for $4 \mathrm{~min}$. Injections $(1 \mu \mathrm{l})$ were made in the split mode with a 50:1 split and a $20 \mathrm{~mm}$ plug of silanised glass wool present in the glass liner of the injector. The carrier gas was He at a head pressure of $76 \mathrm{kPa}$ and the column was connected directly to the ion source of the MS. The MS was operated under electron impact conditions with the following source variables: electron energy $70 \mathrm{eV}$, emission current $300 \mu \mathrm{A}$ and source temperature $200^{\circ} \mathrm{C}$. Selective ion recording was used to monitor the M-57 ions of interest with a dwell time of $30 \mathrm{~ms}$ on each ion. For acetate only the $\mathrm{M}+$ and $\mathrm{M}+1$ ions were monitored, at mass/charge $(\mathrm{m} / \mathrm{z}) 117$ and 118 , but for butyrate $\mathrm{M}+2$ was also quantified to determine any butyrate formed from two $\left[1-{ }^{13} \mathrm{C}\right]$ acetate molecules (i.e. $\mathrm{m} / \mathrm{z}$ 145, 146 and 147 were monitored). In practice, the amounts of double-labelled butyrate formed (i.e. from condensation of two labelled acetate molecules) were close to that predicted by the laws of probability from the square of the acetate enrichment. Enrichments in ${ }^{13} \mathrm{C}$ were expressed as MPE according to the equation:

$$
\text { enrichment }(\mathrm{MPE})=\frac{R i-R o}{1+(R i-R o)} \times 100,
$$

where $R i$ and $R o$ are the ratios of the peak areas for enriched and natural abundance (background) samples respectively. For the concentration determinations, appropriate corrections were applied for the enrichments in the sample.

\section{Kinetic model of acetate metabolism}

Batch cultures. For convenience the model units are expressed as $\mathrm{C}_{2}$ units, i.e. $2 \mathrm{~mol}$ for butyrate formation, while for glucose it is assumed that metabolism of $1 \mathrm{~mol}$ glucose provides $2 \mathrm{~mol}$ acetate (or acetyl-CoA) with the remaining $\mathrm{C}$ lost as $\mathrm{CO}_{2}$. Let $i$ denote a time interval starting at time $t_{0}$ and ending at $t_{1}$. The production of acetate during interval $i$, denoted by $\mathrm{F}_{\mathrm{a}}(i)$, was obtained from the dilution of $\left[1-{ }^{13} \mathrm{C}\right]$ acetate:

$$
\mathrm{F}_{\mathrm{a}}(i)=\left(\frac{\mathrm{E}_{\mathrm{a}}\left(t_{0}\right)}{\mathrm{E}_{\mathrm{a}}\left(t_{1}\right)}-1\right) \times \mathrm{C}_{\mathrm{a}}\left(t_{0}\right)
$$

where $\mathrm{E}_{\mathrm{a}}$ is the acetate enrichment (MPE) and $\mathrm{C}_{\mathrm{a}}\left(t_{0}\right)$ is the acetate concentration at $t_{0}$. Net acetate production during interval $i\left(\mathrm{~F}_{\text {anet }}(i)\right)$ is given by:

$$
\mathrm{F}_{\text {anet }}(i)=\mathrm{C}_{\mathrm{a}}\left(t_{1}\right)-\mathrm{C}_{\mathrm{a}}\left(t_{0}\right) .
$$

A negative value indicates a net loss. Butyrate production during interval $i\left(\mathrm{~F}_{\mathrm{b}}(i)\right)$ is given by:

$$
\mathrm{F}_{\mathrm{b}}(i)=\mathrm{C}_{\mathrm{b}}\left(t_{1}\right)-\mathrm{C}_{\mathrm{b}}\left(t_{0}\right)
$$

where $C_{b}$ is the butyrate concentration. It was assumed that the butyrate is not further metabolised (SH Duncan and GE Lobley, unpublished results) so that net production also reflects total production of butyrate. To determine the contribution of production of butyrate from acetate, the enrichment of the newly produced butyrate was compared with the acetate enrichment. Let $\mathrm{E}_{\mathrm{b}}$ (produced during $i$ ) be the enrichment of the newly produced butyrate (in $\mathrm{C}_{2}$ units) during time interval $i$ :

$$
\begin{aligned}
& \left.\mathrm{E}_{\mathrm{b}} \text { (produced during } i\right) \\
& =\frac{\mathrm{E}_{\mathrm{b}}\left(t_{1}\right) \times \mathrm{C}_{\mathrm{b}}\left(t_{1}\right)-\mathrm{E}_{\mathrm{b}}\left(t_{0}\right) \times \mathrm{C}_{\mathrm{b}}\left(t_{0}\right)}{\mathrm{C}_{\mathrm{b}}\left(t_{1}\right)-\mathrm{C}_{\mathrm{b}}\left(t_{0}\right)} .
\end{aligned}
$$

Since in molar terms $1 \mathrm{~mol}$ butyrate is derived from $2 \mathrm{~mol}$ acetate, then the enrichment of total acetate in singlelabelled $(\mathrm{M}+1)$ butyrate is half that of the butyrate, i.e. $E_{b}=0.5 M E_{b}$. This simplification is possible because of the negligible double-labelled butyrate formed (i.e. where both $\mathrm{C}_{2}$ units derive from $\left[1-{ }^{13} \mathrm{C}\right]$ acetate). Then butyrate production from acetate during time interval $i\left(\mathrm{~F}_{\mathrm{ba}}(i)\right)$ is given by:

$$
\mathrm{F}_{\mathrm{ba}}(i)=\frac{\mathrm{E}_{\mathrm{b}}(\text { produced during } i)}{\mathrm{E}_{\mathrm{a}}(i)} \times \mathrm{F}_{\mathrm{b}}(i),
$$

where $\mathrm{E}_{\mathrm{a}}(i)$ is the average of $\mathrm{E}_{\mathrm{a}}\left(t_{0}\right)$ and $\mathrm{E}_{\mathrm{a}}\left(t_{1}\right)$. Let the final time point be at $T$. For the single-strain batch cultures $T$ was taken when glucose had disappeared i.e. $T=7 \cdot 0,6 \cdot 0,5 \cdot 0$, $14.5,9.0$ and $14.5 \mathrm{~h}$ for strains A2-181, A2-183, L2-50, A2165, L1-82 and L1-8151 respectively. For the mixed culture batch cultures $T$ was taken as $24 \cdot 0 \mathrm{~h}$. To obtain flows 
per $\mathrm{d}$, the flows for each time interval were aggregated and then multiplied by $24 / T$ :

$$
\begin{aligned}
\mathrm{F}_{\mathrm{a}} & =\frac{24}{T} \sum_{i} \mathrm{~F}_{\mathrm{a}}(i) ; \quad \mathrm{F}_{\mathrm{b}}=\frac{24}{T} \sum_{i} \mathrm{~F}_{\mathrm{b}}(i) ; \\
\mathrm{F}_{\mathrm{ba}} & =\frac{24}{T} \sum_{i} \mathrm{~F}_{\mathrm{ba}}(i) ; \quad \mathrm{F}_{\text {anet }}=\frac{24}{T} \sum_{i} \mathrm{~F}_{\text {anet }}(i) .
\end{aligned}
$$

The proportion of butyrate derived from acetate $(p)$ is then given by:

$$
\mathrm{p}=\frac{\mathrm{F}_{\mathrm{ba}}}{\mathrm{F}_{\mathrm{b}}}
$$

For the single-strain batch cultures, the model was extended by including an intracellular $\mathrm{C}_{2}$ pool of acetate and acetyl-CoA, which exchanges with the exogenous acetate pool. It was assumed that butyrate production is via this pool (see later, Fig. 2). Assuming that the molar glucose conversion to $2 \mathrm{~mol}$ acetyl-CoA also flows via the intracellular $\mathrm{C}_{2}$ pool, then:

$$
\begin{gathered}
\text { influx }=\text { glucose } \operatorname{loss} \times \frac{\mathrm{p}}{1-\mathrm{p}} \\
\text { efflux }=\text { influx }-\mathrm{F}_{\text {anet }}
\end{gathered}
$$

Fermentor studies. A single dose $(2 \mathrm{mmol})$ of enriched acetate was added to the fermentor at $t 0$. The enrichment of butyrate as $\mathrm{C}_{2}$ units at time $t$ is given by $\mathrm{E}_{\mathrm{b}}(t)=\operatorname{MPE}_{\mathrm{b}}(t) / 2$. The acetate and butyrate enrichments at time $t$ are then modelled by:

$$
\mathrm{E}_{\mathrm{a}}(t)=\mathrm{A} \times \exp \left(-\mathrm{k}_{\mathrm{a}} \times t\right)
$$

and

$$
\mathrm{E}_{\mathrm{b}}(t)=\mathrm{L} \times\left(\exp \left(-\mathrm{k}_{\mathrm{b}} \times t\right)-\exp \left(-\mathrm{k}_{\mathrm{a}} \times t\right)\right.
$$

where $\mathrm{L}=\mathrm{A} \times \mathrm{k}_{\mathrm{ba}} \times \mathrm{C}_{\mathrm{a}} /\left(\left(\mathrm{k}_{\mathrm{a}}-\mathrm{k}_{\mathrm{b}}\right) \times \mathrm{C}_{\mathrm{b}}\right)$, and $\mathrm{k}_{\mathrm{a}}, \mathrm{k}_{\mathrm{b}}$ and $\mathrm{k}_{\mathrm{ba}}\left(\mathrm{d}^{-1}\right)$ are fractional rate constants (Shipley \& Clark, 1972). Models 1 and 2 were fitted to the acetate and butyrate enrichments giving estimates of $\mathrm{A}, \mathrm{k}_{\mathrm{a}}, \mathrm{L}$ and $\mathrm{k}_{\mathrm{b}}$. Then the acetate flux, butyrate production, and production of butyrate from acetate (denoted by $\mathrm{F}_{\mathrm{a}}, \mathrm{F}_{\mathrm{b}}$ and $\mathrm{F}_{\mathrm{ba}}$ respectively, all in $\mathrm{mmol} \mathrm{C}_{2} / 1$ per $\mathrm{d}$ ) are given by:

$$
\begin{aligned}
& \mathrm{F}_{\mathrm{a}}=\mathrm{k}_{\mathrm{a}} \times \mathrm{C}_{\mathrm{a}}, \\
& \mathrm{F}_{\mathrm{b}}=\mathrm{k}_{\mathrm{b}} \times \mathrm{C}_{\mathrm{b}},
\end{aligned}
$$

and

$$
\mathrm{F}_{\mathrm{ba}}=\mathrm{k}_{\mathrm{ba}} \times \mathrm{C}_{\mathrm{a}}
$$

where

$$
\mathrm{k}_{\mathrm{ba}}=\mathrm{L} \times\left(\mathrm{k}_{\mathrm{a}}-\mathrm{k}_{\mathrm{b}}\right) \times \mathrm{C}_{\mathrm{b}} /\left(\mathrm{A} \times \mathrm{C}_{\mathrm{a}}\right) .
$$

The proportion of butyrate derived from acetate is then:

$$
\mathrm{p}=\frac{\mathrm{F}_{\mathrm{ba}}}{\mathrm{F}_{\mathrm{b}}}
$$

\section{Statistical analyses}

Models 1 and 2 were fitted to the acetate and butyrate enrichments from the fermentor study using non-linear regression in Genstat edition 6 (release 6.1; Lawes Agricultural Trust, Rothamsted, Herts., UK). To test for differences between substrates, ANOVA was applied to the quantities of interest with fermentor as a blocking factor and with substrate as treatment effect.

\section{Results}

Concentrations are expressed conventionally as mM. In contrast, and for ease of comparison, calculations and values in tables describing metabolite flows and mass transfers are expressed in $\mathrm{C}_{2}$ units, i.e. 1 per mol acetate and 2 per mol butyrate. The flow from glucose is taken as two $\mathrm{C}_{2}$ (acetyl-CoA) units, since the $\mathrm{CO}_{2}$ or $\mathrm{HCOOH}$ (formic acid) released in forming acetyl-CoA from pyruvate is here considered irrelevant.

\section{Studies with isolated bacteria}

Incorporation of $\left[{ }^{13} \mathrm{C}\right]$ acetate into butyrate was studied in six strains of anaerobic bacteria (listed in Table 1) representing abundant groups of butyrate-producing bacteria (Roseburia, F. prausnitzii and Coprococcus relatives) from human faeces (Barcenilla et al. 2000). For all the pure strains studied, production of butyrate and consumption (or production) of acetate ceased between 5 and $14 \mathrm{~h}$, concomitant with the disappearance of glucose from the medium (Fig. 1). Similarly, changes in butyrate enrichments and total label incorporation also ceased when all the glucose was consumed (Fig. 2). As observed previously (Barcenilla et al. 2000), four of the anaerobic bacterial strains (Roseburia spp. A2-181, A2-183, L1-82, L1-8151) isolated from human faeces showed some net utilisation of the acetate initially present in the growth medium (Table 1). These strains also gave the highest net production of butyrate $\left(42-72 \mathrm{mmol} \mathrm{C}_{2} / \mathrm{d}\right.$ per 1; Table 1). Two strains, Roseburia sp. A2-183 and F. prausnitzii A2165 , consumed little or no acetate and their butyrate production matched utilisation of $\mathrm{C}_{2}$ units from glucose (Table 1). Despite this, in all of these strains the proportion of butyrate-C derived from acetate, based on ${ }^{13} \mathrm{C}$ transfers, was $>85 \%$ (Table 1). This was best explained by fitting a model that included considerable interchange of extracellular and intracellular acetate across the cell membrane. This model allowed for estimation of the absolute inward and outward transport rates (Fig. 3; Table 1).

In contrast, the Coprococcus-related strain L2-50 was a net acetate producer with only small amounts of butyrate synthesised. Of this, only $28 \%$ was derived from acetate and little exchange occurred between extracellular and intracellular acetate (Table 1).

\section{Effect of substrate on acetate metabolism and butyrate production by mixed faecal bacteria}

Duplicate continuous culture vessels that received identical faecal inocula were used to investigate the influence of 
Table 1. Medium concentrations, net mass changes $\left(\mathrm{mmol} \mathrm{C}_{2} / \mathrm{d}\right.$ per I) and flows between acetate, butyrate and glucose in bacterial strains isolated from human faeces*

\begin{tabular}{|c|c|c|c|c|c|c|}
\hline & \multicolumn{2}{|c|}{ Roseburia sp. } & \multicolumn{2}{|c|}{ Roseburia intestinalis } & \multirow{2}{*}{$\frac{\text { Coprococcus-like }}{\text { L2-50 }}$} & \multirow{2}{*}{$\begin{array}{c}\begin{array}{c}\text { Faecalibacterium } \\
\text { prausnitzii }\end{array} \\
\text { A2-165 }\end{array}$} \\
\hline & A2-181 & A2-183 & L1-82 & L1-8151 & & \\
\hline \multicolumn{7}{|l|}{ Concentrations (mм) } \\
\hline Acetate at $t 0$ & $56 \cdot 0$ & 53.8 & 61.4 & $60 \cdot 6$ & 54.5 & $57 \cdot 1$ \\
\hline Acetate at $T \mathrm{~d}$ & $50 \cdot 1$ & 53.2 & $53 \cdot 8$ & $49 \cdot 6$ & $55 \cdot 6$ & 57.5 \\
\hline Butyrate at $T d$ & $10 \cdot 9$ & $9 \cdot 0$ & $12 \cdot 4$ & $13 \cdot 3$ & $1 \cdot 7$ & $9 \cdot 4$ \\
\hline \multirow{2}{*}{\multicolumn{7}{|c|}{$\begin{array}{l}\text { Flows }\left(\mathrm{mmol} \mathrm{C}_{2} / \mathrm{d} \text { per I) }\right. \\
\text { Net balance }\end{array}$}} \\
\hline & & & & & & \\
\hline Acetate $\left(F_{\text {anet }}\right)$ & $-20 \cdot 3$ & $-2 \cdot 3$ & $-20 \cdot 2$ & $-18 \cdot 2$ & $5 \cdot 4$ & $0 \cdot 6$ \\
\hline Glucose & $-65 \cdot 8$ & $-65 \cdot 8$ & $-44 \cdot 2$ & $-34 \cdot 2$ & $-8 \cdot 1$ & $-29 \cdot 8$ \\
\hline Butyrate $\left(F_{b}\right)$ & 71.7 & $67 \cdot 7$ & 63.9 & $42 \cdot 3$ & $12 \cdot 4$ & 29.5 \\
\hline Acetate production $\left(\mathrm{F}_{\mathrm{a}}\right)$ & $51 \cdot 3$ & 47.5 & $48 \cdot 6$ & $32 \cdot 8$ & $6 \cdot 0$ & 20.5 \\
\hline \multicolumn{7}{|l|}{ Butyrate formed: } \\
\hline From acetate $\left(\mathrm{F}_{\mathrm{ba}}\right)$ & $62 \cdot 6$ & $59 \cdot 8$ & $57 \cdot 2$ & 37.9 & 3.4 & $26 \cdot 5$ \\
\hline From other & $9 \cdot 1$ & $7 \cdot 9$ & $6 \cdot 7$ & 4.4 & $9 \cdot 0$ & 3.0 \\
\hline Proportion from acetate $(p)$ & 0.87 & 0.88 & 0.89 & 0.90 & 0.28 & 0.90 \\
\hline \multicolumn{7}{|l|}{ Transmembrane transport } \\
\hline Influx & 453 & 501 & 376 & 293 & $3 \cdot 1$ & 263 \\
\hline Efflux & 432 & 499 & 356 & 275 & 8.5 & 263 \\
\hline
\end{tabular}

$T d$, time point at which glucose had disappeared (see p. 917).

${ }^{*}$ For details of the kinetic model, see p. 917.

alternative polysaccharide energy sources upon fermentation. Acetate concentrations remained stable over the $7 \mathrm{~d}$ of incubation and ranged from $20.2 \mathrm{~mm}$ (shredded wheat) to $28.8 \mathrm{~mm}$ (pectin; Table 2). These concentrations were considerably in excess of that in the inflow medium $(2.5 \mathrm{~mm})$ and indicated that substantial net acetate production occurred within the fermentors for all substrates. Butyrate concentrations were greatest with amylopectin $(5.3 \mathrm{~mm})$ and lowest with pectin $(3.1 \mathrm{~mm})$ as substrate (Table 2), while propionate concentrations ranged from $9.1 \mathrm{~mm}$ (pectin) to $26 \cdot 8 \mathrm{~mm}$ (mixed substrate; Table 2 ).

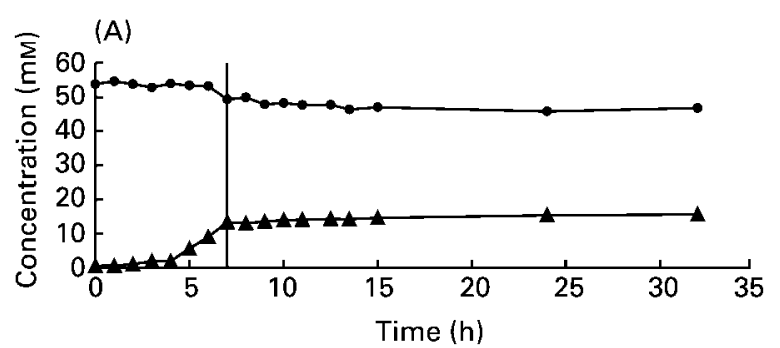

(C)

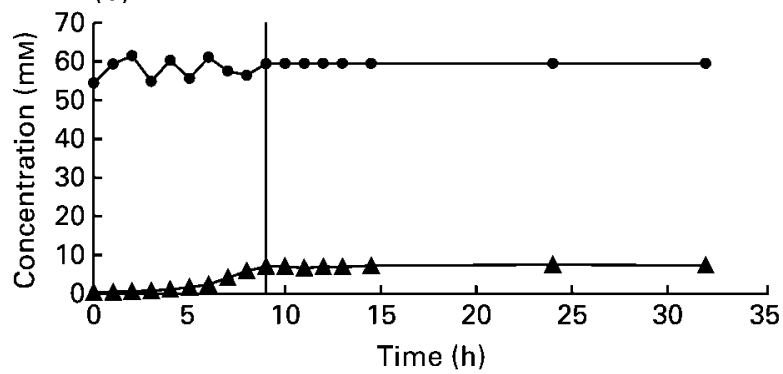

For all fermentors, a single exponential model fitted well the kinetics of $\left[{ }^{13} \mathrm{C}\right]$ acetate-enrichments (illustrated for xylan, Fig. 4), with $>93 \%$ of the observed variance accounted (results not shown). For all substrates, $<42 \%$ of the acetate flux through the fermentor was due to the infusion, the remainder being a consequence of carbohydrate fermentation. Butyrate productions were in proportion to butyrate concentrations and encompassed a twofold range for single carbohydrate sources in the order amylopectin $>$ xylan $>$ shredded wheat $>$ dahlia inulin $>$ chicory inulin $>$ pectin. In all cases, the majority

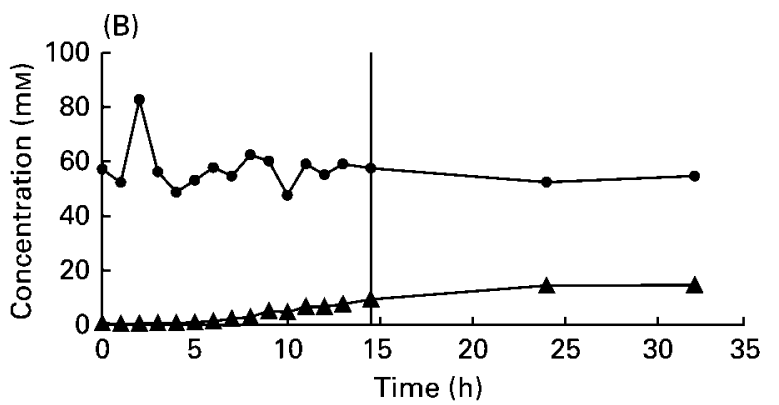

(D)

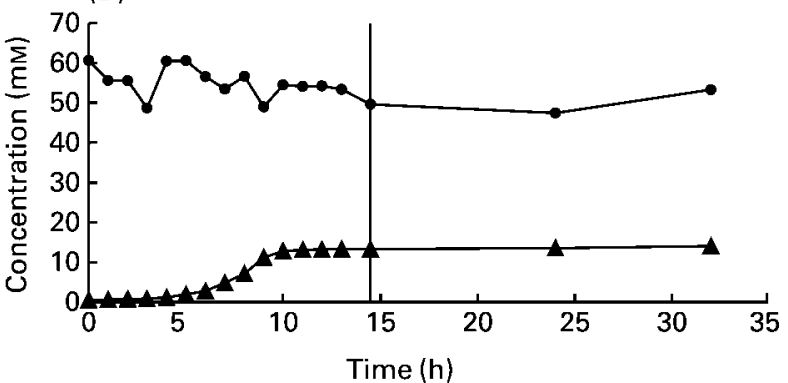

Fig. 1. Concentrations of acetate $(\bullet)$ and butyrate $(\mathbf{\Lambda})$ detected in the media during incubation of Roseburia-like isolate sp. A2-183 (A), Faecalibacterium prausnitzii A2-165 (B), Coprococcus-like sp. L2-250 (C) and R. intestinalis L1-8151 (D). I, Time at which glucose was depleted. For details of procedures, see p. 917. 
(A)

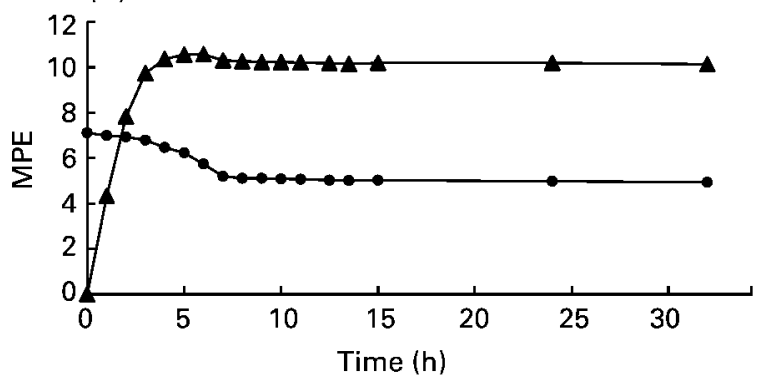

(C)

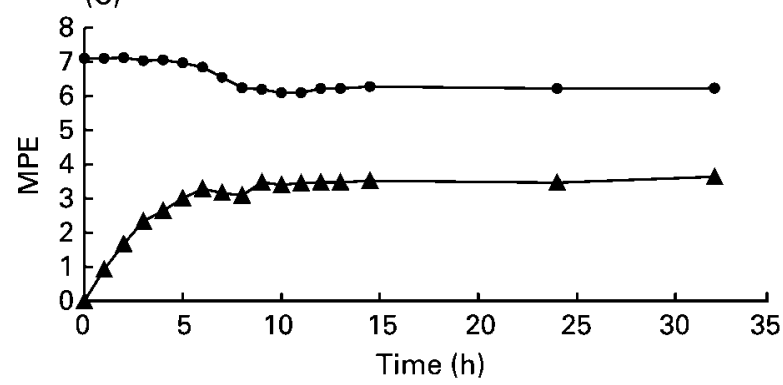

(B)

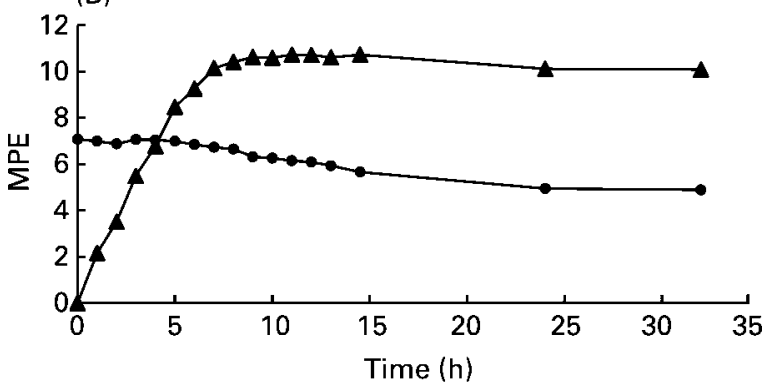

(D)

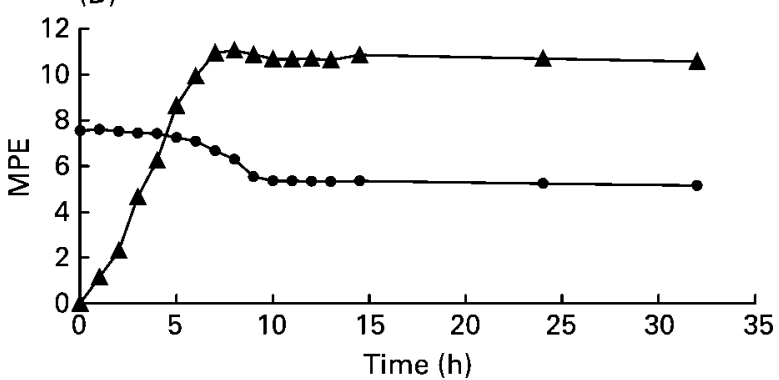

Fig. 2. Molar \% excess (MPE) for acetate $(\bullet)$ and butyrate $(\mathbf{\Lambda})$ detected in the media during incubation of Roseburia-like isolate sp. A2-183 (A), Faecalibacterium prausnitzii A2-165 (B), Coprococcus-like sp. L2-250 (C) and R. intestinalis L1-8151 (D) in the presence of $\left[{ }^{13} \mathrm{C}\right]$ acetate. For details of procedures, see p. 917.

of butyrate-C arose from external acetate, with contributions ranging from 56 (pectin) to 90 (xylan) \%.

The simplified batch culture technique for the faecal samples yielded similar qualitative results to the fermentors with regard to butyrate production (Tables 3 and 4). When corrected for basal conditions (utilisation of peptones and other constituents of the medium) net use of $10-\mathrm{mm}$ glucose was matched by quantitative production of acetate and butyrate in 2:3 proportion (expressed as $C_{2}$ units). Most substrates showed net production of acetate, except for amylopectin (zero) and dahlia inulin (net consumption). Butyrate production rates differed fivefold between substrates in the order dahlia inulin $>$ amylopectin $>$ xylan
$>$ shredded wheat $>$ pectin (Table 3 ). The most notable difference with the fermentor data was the improved butyrogenesis with dahlia inulin. For most substrates the proportion of butyrate carbon derived from exogenous acetate was similar to that observed with the fermentor (c.f. Tables 2 and 3), the exceptions were dahlia inulin and pectin, where both showed greater contributions during the batch culture incubations. Interestingly, when the initial acetate concentration was doubled (from 30 to $60 \mathrm{~mm}$ ) in the presence of amylopectin the contribution to butyrate-C was also substantially increased, although there was no obvious effect on butyrate production.

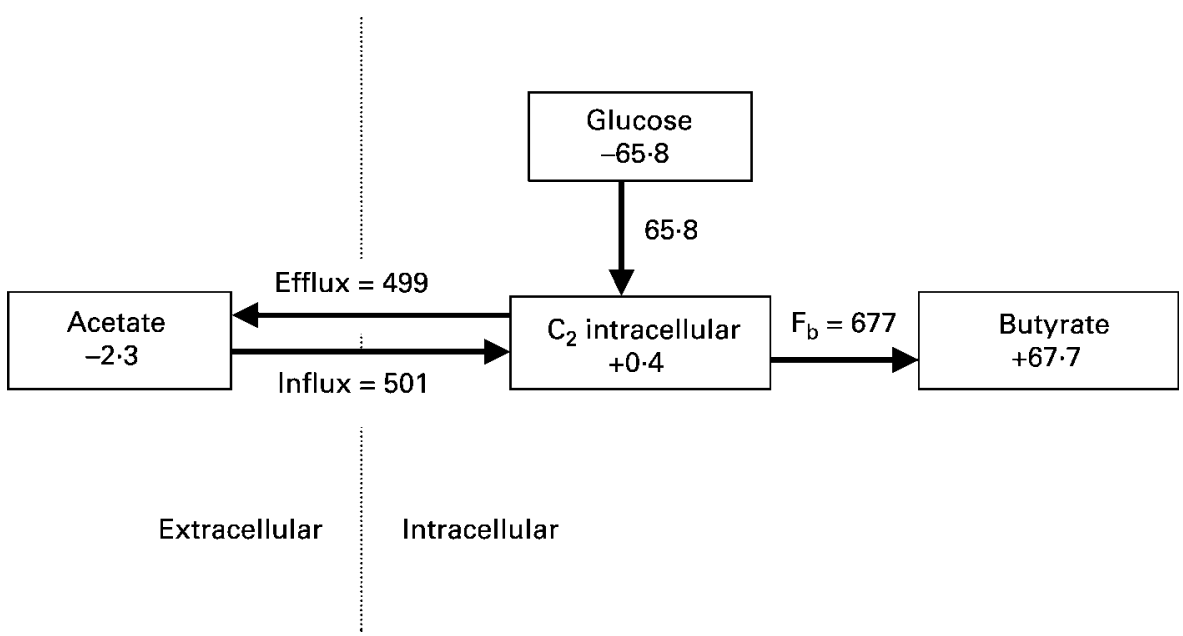

Fig. 3. Transfers ( $\mathrm{mmol} \mathrm{C} / \mathrm{d}$ per I) between glucose, acetate and butyrate in cultures of Roseburia sp. A2-183, calculated from the kinetic model described on p. 917 . Values in the boxes represent the net change in substrate pools. Fb, butyrate production; $\rightarrow$, $\leftarrow$, Flow between pools. For details of procedures, see p. 917 . The value of +0.4 for intracellular $\mathrm{C}_{2}$ refers to the difference between butyrate formation and glucose plus acetate input. This may reflect the increase in total intracellular $\mathrm{C}_{2}$ units due to growth in cell numbers. Although the strain shown here gave little net acetate uptake, acetate uptake was significant in other related strains. 
Table 2. Concentrations and flows for acetate and butyrate in colonic fermentors fed a range of model substrates* (duplicate values)

\begin{tabular}{|c|c|c|c|c|c|c|c|c|c|}
\hline & Mixed & Amylopectin & Pectin & $\begin{array}{c}\text { Inulin } \\
\text { (dahlia?) }\end{array}$ & Xylan & $\begin{array}{c}\text { Inulin } \\
\text { (chicory?) }\end{array}$ & Shredded wheat & SEM† & $P \dagger$ \\
\hline \multicolumn{10}{|l|}{ Concentrations (mM) } \\
\hline Acetate & $27 \cdot 2$ & $22 \cdot 3$ & $28 \cdot 7$ & $23 \cdot 8$ & $21 \cdot 7$ & $23 \cdot 7$ & $20 \cdot 2$ & $6 \cdot 72$ & 0.012 \\
\hline Butyrate & 4.9 & $5 \cdot 3$ & $3 \cdot 1$ & 3.7 & $4 \cdot 2$ & 3.4 & 4.7 & 3.54 & $<0.001$ \\
\hline Propionate & $26 \cdot 8$ & $22 \cdot 3$ & $9 \cdot 1$ & $14 \cdot 3$ & $12 \cdot 2$ & $17 \cdot 3$ & $11 \cdot 2$ & 3.54 & $<0.001$ \\
\hline \multicolumn{10}{|l|}{ Flows (mmol $\mathrm{C}_{2} / \mathrm{d}$ per I) } \\
\hline Acetate flux $\left(F_{a}\right)$ & 31.9 & $26 \cdot 2$ & 28.4 & $25 \cdot 5$ & 31.7 & $33 \cdot 0$ & 24.9 & 1.52 & 0.036 \\
\hline Butyrate production $\left(\mathrm{F}_{\mathrm{b}}\right)$ & $10 \cdot 7$ & $10 \cdot 9$ & $5 \cdot 6$ & $7 \cdot 7$ & $9 \cdot 8$ & $5 \cdot 8$ & $8 \cdot 8$ & 0.39 & $<0.001$ \\
\hline From acetate $\left(\mathrm{F}_{\mathrm{ba}}\right)$ & $6 \cdot 4$ & $8 \cdot 3$ & $3 \cdot 1$ & $5 \cdot 2$ & 8.9 & $5 \cdot 0$ & $7 \cdot 4$ & 0.32 & $<0.001$ \\
\hline From other & 4.3 & $2 \cdot 7$ & 2.4 & 2.5 & 0.9 & 0.8 & 1.5 & 0.33 & 0.003 \\
\hline Proportion from acetate $(p)$ & 0.60 & 0.76 & 0.56 & 0.68 & 0.90 & 0.87 & 0.83 & 0.03 & 0.001 \\
\hline
\end{tabular}

${ }^{*}$ For details of kinetic models and procedures, see p. 917

†From ANOVA with fermentor and substrate as treatment effects. $P$ value for effect of substrate, 6 residual df.

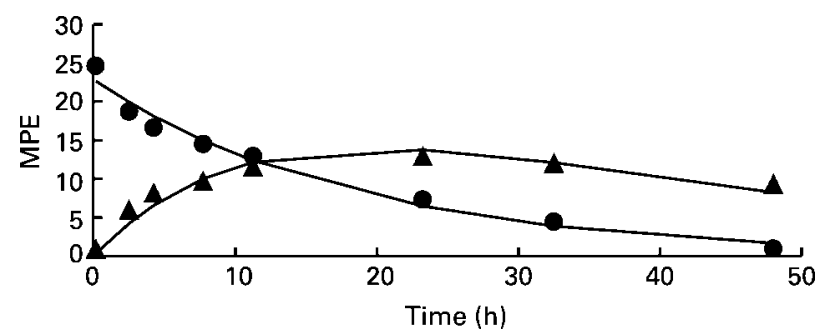

Fig. 4. Molar \% excess (MPE) for acetate $(\bullet)$ and butyrate $(\mathbf{\Delta})$ and fitted curves for the xylan substrate for one of the fermentors from the fermentor study (based on the kinetic model described on p. 917). For details of procedures, see p. 917.

\section{Discussion}

There is much interest in using nutritional manipulation to optimise SCFA (and in particular butyrate) production in the large intestine so as to provide appropriate sources of energy to tissue epithelial cells to help in the prevention of cancer and colitis. This requires an understanding of the responses of key groups of gut bacteria to dietary energy sources that are available in the large bowel.

\section{Metabolism of butyrate-producing bacteria}

The present study and previous studies (Barcenilla et al. 2000) have clearly demonstrated that the Roseburia spp. and $F$. prausnitzii strains present in human faeces produce butyrate and in many strains this is associated with net consumption of both acetate and carbohydrate. In net terms, glucose appeared to dominate the $\mathrm{C}$ mass balance in pure batch cultures provided with $10 \mathrm{mM}$-glucose and $60 \mathrm{~mm}$ acetate, but the isotope studies indicated that most of the butyrate-C (approximately $85 \%$ ) was derived from external acetate, with only $15 \%$ arising directly from glucose. Since butyrate synthesis ceased when the glucose supply was exhausted, carbohydrate is apparently required, probably to provide a source of reducing power for butyrate synthesis from acetyl-CoA as well as energy for growth. At the same time, these strains show active interchange between internal and external $\mathrm{C}_{2}$ pools (Fig. 3), with inflow from external acetate nearly sixfold the production of $\mathrm{C}_{2}$-units from glucose. The role of this rapid exchange remains unclear, but may be linked to the observation that both $F$. prausnitzii and Roseburia spp. apparently lack butyrate kinase activity and, instead, rely on butyryl CoA: acetate CoA transferase for butyrate synthesis (Duncan et al. 2002a). Butyryl CoA: acetate CoA transferase appears to be a soluble enzyme (Duncan et al. 2002a) that depends on cytosolic acetate as a substrate.

Other groups of human faecal bacteria that produce butyrate exhibit different behaviour, however. In the Coprococcus-related strain L2-50, for example, the majority of butyrate-C probably arose from glucose, with

Table 3. Medium concentrations, net mass changes and flows between acetate and butyrate in batch culture incubations on a range of model substrates*

\begin{tabular}{|c|c|c|c|c|c|c|c|c|}
\hline & Basal & $\begin{array}{l}\text { Glucose } \\
(10 \mathrm{~mm})\end{array}$ & Amylopectin & Amylopectin† & Pectin & $\begin{array}{l}\text { Inulin } \\
\text { (dahlia) }\end{array}$ & Xylan & Shredded wheat \\
\hline \multicolumn{9}{|l|}{ Concentration (mM) } \\
\hline \multicolumn{9}{|l|}{$\begin{array}{l}\text { Flows }\left(\mathrm{mmol} \mathrm{C}_{2} / \mathrm{d} \text { per I) }\right. \\
\text { Net balance }\end{array}$} \\
\hline Acetate & $2 \cdot 2$ & $10 \cdot 3$ & 0.4 & $6 \cdot 9$ & $11 \cdot 7$ & -11.4 & $5 \cdot 0$ & $4 \cdot 6$ \\
\hline Butyrate $\left(F_{b}\right)$ & $4 \cdot 3$ & $16 \cdot 2$ & $35 \cdot 6$ & $33 \cdot 6$ & $8 \cdot 2$ & $43 \cdot 8$ & $24 \cdot 1$ & $16 \cdot 8$ \\
\hline Acetate production $\left(\mathrm{F}_{\mathrm{a}}\right)$ & $6 \cdot 2$ & $21 \cdot 8$ & $44 \cdot 8$ & $50 \cdot 8$ & $18 \cdot 8$ & $52 \cdot 7$ & $24 \cdot 1$ & $21 \cdot 2$ \\
\hline \multicolumn{9}{|l|}{ Butyrate formed: } \\
\hline From acetate & 1.9 & $14 \cdot 3$ & $25 \cdot 6$ & $30 \cdot 7$ & $6 \cdot 2$ & $36 \cdot 0$ & $20 \cdot 3$ & $12 \cdot 2$ \\
\hline From other & $2 \cdot 4$ & 1.9 & $10 \cdot 1$ & 2.9 & $2 \cdot 0$ & $7 \cdot 7$ & $3 \cdot 9$ & $4 \cdot 6$ \\
\hline Proportion from acetate $(p)$ & 0.44 & 0.88 & 0.72 & 0.91 & 0.76 & 0.82 & 0.84 & 0.72 \\
\hline
\end{tabular}

* For details of kinetic models and procedures, see p. 917.

† Indicates that the start concentration of acetate was $60 \mathrm{~mm}$ (instead of about $30 \mathrm{~mm}$ as in the other incubations). 
Table 4. Change in concentrations of the three major SCFA (acetate, propionate and butyrate) during batch culture incubations $(48 \mathrm{~h})^{*}$

(Mean values and standard deviations for three replicates)

\begin{tabular}{|c|c|c|c|c|c|c|}
\hline \multirow[b]{3}{*}{ Substrate } & \multicolumn{6}{|c|}{ Increase in SCFA concentration (mM)† } \\
\hline & \multicolumn{2}{|c|}{ Acetate } & \multicolumn{2}{|c|}{ Propionate } & \multicolumn{2}{|c|}{ Butyrate } \\
\hline & Mean & SD & Mean & SD & Mean & SD \\
\hline Basal & 8.79 & $1 \cdot 20$ & $1 \cdot 29$ & 0.20 & 3.55 & $0 \cdot 13$ \\
\hline Glucose (10 mm) & $10 \cdot 67$ & 1.91 & 2.03 & 0.17 & 9.96 & 0.19 \\
\hline Amylopectin & $11 \cdot 81$ & 3.44 & 3.80 & 0.82 & $18 \cdot 20$ & $2 \cdot 20$ \\
\hline Amylopectin $\ddagger$ & $6 \cdot 22$ & 3.49 & 4.62 & 0.85 & $20 \cdot 03$ & 0.69 \\
\hline Pectin & 13.97 & 3.28 & $2 \cdot 61$ & 0.31 & $5 \cdot 80$ & 0.14 \\
\hline Inulin & $8 \cdot 61$ & 1.83 & $2 \cdot 32$ & 1.02 & 33.29 & 0.39 \\
\hline Xylan & 3.44 & 4.86 & $2 \cdot 26$ & 0.48 & $13 \cdot 76$ & 0.62 \\
\hline Shredded wheat & $6 \cdot 79$ & 3.58 & 3.91 & $1 \cdot 24$ & $12 \cdot 48$ & 4.42 \\
\hline
\end{tabular}

* For details of kinetic models and procedures, see p. 917.

†i.e. After subtracting any SCFA present in the medium initially (normally $30 \mathrm{~mm}$ in the case of acetate).

¥Indicates that the start concentration of acetate was $60 \mathrm{~mm}$ (instead of about $30 \mathrm{~mm}$ as in the other incubations).

exogenous acetate contributing only $28 \%$. This strain is a net producer of acetate and, although possessing butyryl CoA: acetate CoA transferase, also contains butyrate kinase (Duncan et al. 2002a). This latter reaction allows energy recovery as ATP when butyryl CoA is converted to butyrate via butyryl phosphate. Thus, the dependence on maintaining acetyl-CoA concentrations would be less important. The reasons for less rapid exchange between external and cytosolic acetate in strain L2-50 compared with the other strains are unclear but might reflect, for example, lower rates of conversion of acetate to acetylCoA within the cell.

Evidence indicates that $F$. prausnitzii and the Roseburia sp./E. rectale are normally the two most abundant groups of human faecal bacteria that produce butyric acid, together accounting for approximately $7 \%$ total faecal bacteria in samples from ten healthy individuals, while Coprococcus-like bacteria are less abundant (Hold et al. 2003). Even higher estimates of abundance have been reported for F. prausnitzii (Suau et al. 2001). The extent of acetate incorporation into butyrate in the mixed faecal incubations performed here is consistent with bacteria of the Roseburia/F. prausnitzii metabolic type contributing to $75-100 \%$ of butyrate formation from all substrates except pectin, where incorporation was lower. Previous studies with human faeces using labelled $\mathrm{CO}_{2}$ or labelled glucose also indicated indirectly that acetate can contribute 80-100\% (Miller \& Wolin, 1996) or 50-65\% (Wolin et al. 1999) of butyrate-C, based on the relative labelling of acetate and butyrate.

While the metabolic type of butyrate producer represented by Roseburia and F. prausnitzii apparently predominates in faeces, it remains possible that certain substrates, such as pectin, can alter the proportions of the two main metabolic types of butyrate-producing bacteria identified here within the colon. In addition we do not rule out the interesting possibility that these proportions might differ markedly in some individuals; only a single faecal donor was used in the present study.

\section{Impact of carbohydrate source}

Continuous flow fermentors allow the long-term impact of carbohydrate sources and their metabolism to be monitored under steady-state conditions. The conditions studied here are probably closest to those in the lumen of the transverse colon, since $\mathrm{pH}$ may be somewhat $<6.5$ proximally and slightly higher distally (Macfarlane \& Gibson, 1997). Use was also made here of the quicker batch culture approach. Both fluxes and transfers needed to be determined in order to compare butyrate production between these two systems: simple comparison of concentrations would be misleading because there is continuous liquid outflow (and inflow) in the open system, while SCFA accumulate in the closed-batch system. It should also be noted that since the continuous flow fermentor experiment involved presenting different carbohydrate sources in succession, it cannot be ruled out that the order of substrate addition could have been a factor affecting the fermentation of a given substrate (Duncan et al. 2003).

In fact most of the carbohydrate sources gave similar relative butyrate outputs, with pectin being the least butyrogenic substrate in both batch and continuous flow systems, but dahlia inulin produced the most butyrate in the batch cultures, and amylopectin the most in the continuous cultures. These findings are in agreement with previous in vitro studies (e.g. Englyst et al. 1987; Titgemeyer et al. 1991; Weaver et al. 1992; Duncan et al. 2003). Inulin and starch have been reported to be butyrogenic in in vivo studies in human subjects and in gnotobiotic rats with a human-associated microflora (Weaver et al. 1992; Wolin et al. 1999; Kleessen et al. 2001; Topping \& Clifton, 2001).

A marked difference between batch and continuous culture systems was seen in the relative production of butyrate and propionate, with higher proportions of the latter being produced in the open system than in batch culture, although the same medium and faecal donor were used in both cases. This could be related to the lack of $\mathrm{pH}$ control and endproduct removal in the batch incubations, to differences in $\mathrm{O}_{2}$ levels, or to shifts in the fermentor community during the initial $7 \mathrm{~d}$ equilibration period.

In conclusion, the net and dynamic contributions of acetate to butyrate formation by mixed human faecal bacteria appear consistent with the behaviour of isolated bacteria related to Roseburia spp. and $F$. prausnitzii in pure culture; this implies a major role for these bacteria in butyrate synthesis in vivo. Most of the carbohydrate sources tested, with the possible exception of pectin, appear suitable as butyrogenic substrates, despite the fact that they do not necessarily support growth of the individual butyrate-producing bacterial species in pure culture. It is clear from this work, and from other studies (Duncan et al. 2002b), that the major butyrogenic species depend for their survival and activities on other bacteria, including net producers of acetate and species capable of degrading a variety of complex carbohydrates. A possible factor in the reported butyrogenic effect of resistant starch, for example, might be that acetate produced by amylolytic bifidobacteria became re-routed into butyrate by bacteria such as those considered here. Nutritional strategies aimed at delivering butyrate to the human colon need to take these interactions into account. 


\section{Acknowledgements}

We thank Kenneth Young for technical assistance and Susan Anderson for GC-MS analysis. We are grateful to Karen Scott and Tony Richardson for their help with the fermentor studies. The Rowett Research Institute and Biomathematics and Statistics Scotland (BioSS) receive financial support from the Scottish Executive Environment and Rural Affairs Department (SEERAD).

\section{References}

Avivi-Green C, Polak-Charson S, Madar Z \& Schwartz B (2000) Apoptosis cascade proteins are regulated in vivo by high intracolonic butyrate concentration: correlation with colon cancer inhibition. Oncol Res 12, 83-95.

Barcenilla A, Pryde SE, Martin JC, Duncan SH, Stewart CS, Henderson C \& Flint HJ (2000) Phylogenetic relationships of dominant butyrate producing bacteria from the human gut. Appl Environ Microbiol 66, 1654-1661.

Bryant MP (1972) Commentary on the Hungate technique for cultivation of anaerobic bacteria. Am J Clin Nutr 25, 1324-1328.

Calder AG, Garden KE, Anderson SE \& Lobley GE (1999) Quantitation of blood and plasma amino acids using isotope dilution electron impact gas chromotography/mass spectrometry with U-13C amino acids as internal standards. Rapid Commun Mass Spectrom 13, 2080-2083.

Cavaglieri C, Nishiyama A, Fernandes LC, Curi R, Miles EA \& Calder PC (2003) Differential effects of short chain fatty acids on proliferation and production of pro- and anti-inflammatory cytokines by cultured lymphocytes. Life Sci 73, 1683-1690.

Csordas A (1996) Butyrate, aspirin and colorectal cancer. Eur J Cancer Prev 5, 221-231.

Cummings HJ (1995) Short chain fatty acids. In Human Colonic Bacteria: Role in Nutrition, Physiology and Pathology, pp. 101-130 [GR Gibson and GT Macfarlane]. Boca Raton, FL: CRC Press.

Duncan SH, Barcenilla A, Stewart CS, Pryde SE \& Flint HJ (2002a) Acetate utilization and butyryl coenzyme A (CoA): acetate-CoA transferase in butyrate-producing bacteria from the human large intestine. Appl Environ Microbiol 68, 5186-5190.

Duncan SH, Hold GL, Barcenilla A, Stewart CS \& Flint HJ (2002b) Roseburia intestinalis sp. nov., a novel saccharolytic, butyrate-producing bacterium from human faeces. Int $J$ Syst Evol Microbiol 52, 1615-1620.

Duncan SH, Hold GL, Harmsen HJM, Stewart CS \& Flint HJ (2002c) Growth requirements and fermentation products of Fusobacterium prausnitzii, and a proposal to reclassify it as Faecalibacterium prausnitzii gen. nov., comb. nov. Int J Syst Evol Microbiol 52, 2141-2146.

Duncan SH, Scott KP, Ramsay AG, Harmsen HJM, Welling GW, Stewart CS \& Flint HJ (2003) Effects of alternative dietary substrates on competition between human colonic bacteria in an anaerobic fermentor system. Appl Environ Microbiol 69, $1136-1142$

Englyst HN, Hay S \& Macfarlane GT (1987) Polysaccharide breakdown by mixed populations of human fecal bacteria. FEMS Microbiol Ecol 95, 163-171.

Hague A, Elder DJE, Hicks DJ \& Paraskeva AC (1995) Apoptosis in colorectal tumour cells - induction by the short chain fatty acids butyrate, propionate and acetate and acetate by the bile salt deoxycholate. Int J Cancer 60, 400-406.

Hillman K, Murdoch TA, Spencer RJ \& Stewart CS (1994) Inhibition of enterotoxigenic Escherichia coli by the microflora of the porcine ileum, in an in vitro semi-continuous culture system. J Appl Bacteriol 76, 294-300.
Hold GL, Schwiertz A, Aminov RI, Blaut M \& Flint HJ (2003) Oligonucleotide probes that detect quantitatively significant groups of butyrate-producing bacteria in human feces. Appl Environ Microbiol 69, 4320-4324.

Kleessen B, Hartmann L \& Blaut M (2001) Oligofructose and long chain inulin: influence on the gut microbial ecology of rats associated with a human faecal flora. Br J Nutr 86, 291-300.

Macfarlane GT \& Gibson GR (1997) Carbohydrate fermentation, energy transduction and gas metabolism in the human large intestine. In Gastrointestinal Microbiology, vol. 1. pp. 269-318 [RI Mackie and BA White, editors]. New York: B. A. Chapman and Hall Microbiology Series.

Macfarlane GT, Hay S \& Gibson GR (1989) Influence of mucin on glycosidase, protease and arylamidase activities of human gut bacteria grown in a 3-stage continuous culture system. J Appl Bacteriol 66, 407-417.

McIntyre A, Gibson PR \& Young GP (1993) Butyrate production from dietary fiber and protection against large bowel cancer in a rat model. Gut 34, 386-391.

Mariadason JM, Corner GA \& Augenlight LH (2000) Genetic reprogramming in pathways of colonic cell maturation induced by short chain fatty acids: comparison with trichostatin A, sulindac, and curcurmin and implications for chemoprevention of colon cancer. Cancer Res 60, 4561-4572.

Miller TL \& Wolin MJ (1996) Pathways of acetate, propionate, and butyrate formation by the human fecal microbial flora Appl Environ Microbiol 62, 1589-1592.

Miyazaki K, Martin JC, Marinsek-Logar R \& Flint HJ (1997) Degradation and utilisation of xylans by the rumen anaerobe Prevotella bryantii (formerly $P$. ruminicola subsp. brevis) $\mathrm{B}_{1} 4$. Anaerobe 3, 373-381.

Pryde SE, Duncan SH, Hold GL, Stewart CS \& Flint HJ (2002) The microbiology of butyrate formation in the human colon. FEMS Microbiol Letts 217, 133-139.

Richardson AJ, Calder GC, Stewart CS \& Smith A (1989) Simultaneous determination of volatile and non-volatile fermentation products of anaerobes by capillary gas chromatography. Lett Appl Microbiol 9, 5-8.

Scheppach W, Luehrs H \& Menzel T (2001) Beneficial health effects of low digestible carbohydrate consumption. $\mathrm{Br} \mathrm{J}$ Nutr 85, S23-S30.

Shipley RA \& Clark RE (1972) Tracer Methods for In Vivo Kinetics, Theory and Applications. New York: Academic Press, New York.

Suau A, Rochet V, Sghir A, Gramet G, Breways S, Sutern M, Rigottier-Gois L \& Dore J (2001) Fusobacterium prausnitzii and related species represent a dominant group within the human fecal flora. Syst Appl Microbiol 24, 139-145.

Titgemeyer EC, Bourquin LD, Fahey GC Jr \& Garleb KA (1991) Fermentability of various fiber sources by human fecal bacteria in vitro. Am J Clin Nutr 53, 1418-1424.

Topping DL \& Clifton PM (2001) Short chain fatty acids and human colonic function: roles of resistant starch and nonstarch polysaccharides. Physiol Rev 81, 1031-1064.

Wachtershauser A \& Stein J (2000) Rationale for the luminal provision of butyrate in intestinal disease. Eur J Nutr 39, 164-171.

Weaver GA, Krause JA, Miller TL \& Wolin MJ (1992) Cornstarch fermentation by the colonic microbial community yields more butyrate than does cabbage fibre fermentation cornstarch fermentation rates correlate negatively with methanogenesis. Am J Clin Nutr 55, 70-77.

Wolin MJ, Miller TJ, Yerry S, Zhang YC, Bank S \& Weaver GA (1999) Changes in fermentation pattern of fecal microbial communities associated with a drug treatment that increases dietary starch in the human colon. Appl Environ Microbiol 65, $2807-2812$. 